\title{
DIERPORTRETTEN IN STEEN IN ZUID-AZIË DOOR DE EEUWEN HEEN
}

In Mamallapuram, Tamil Nadu, liggen vlak aan het strand her en der verspreid enorme rotsblokken. Een deel daarvan is tijdens de Pallava dynastie ( $7^{\mathrm{e}}$-midden $8^{\mathrm{e}}$ eeuw) omgetoverd tot driedimensionale sculpturen zoals vrijstaande rijdieren der goden of kleine tempeltjes. Vaak is niets van het oorspronkelijke rotsblok origineel gebleven. Een ander deel is gedeeltelijk bewerkt, tot tweedimensionale mythische voorstellingen. Een daarvan staat bekend als Arjuna's Boetedoening ( $\mathrm{afb}$. 1), waarschijnlijk naar het epische gedicht Kiratarjuniya van Bharavi, een $6^{\mathrm{e}}$-eeuwse dichter uit het nabije Kanchipuram. Het paneel is tot in de kleinste hoekjes opgevuld met goden, helden, mensen, dieren en mythische wezens. De enorme verzameling dieren is op weg naar de Ganges rivier. De uitgehouwen dieren omvatten bijna ieder wild zoogdier, reptiel en vogel die wijdverbreid zijn in de Indische iconografie, ${ }^{1}$ behalve vreemd genoeg het wilde zwijn. ${ }^{2}$

Deze alom bekende wilde dieren blijken leeuwen, herten, beren, apen, ${ }^{3}$ katten, muizen en ratten, schildpadden, hagedissen, krokodillen, ganzen en pauwen te zijn. De rest is eenvoudigweg blijkbaar overal elders ook onbekend en/of onbemind en wordt vaak maar op een enkele sculptuur aangetroffen. Afbeeldingen van Indiase bizons, nilgai (Boselaphus tragocamelus), steenbokken, wilde geiten en schapen, antilopen en gazelles, tapirs, eekhoorns, jakhalzen, rode honden, hazen, otters, luipaarden, tijgers, neushoorns en vossen zijn buitengewoon zeldzaam, vooral in relatie tot de overweldigende totale hoeveelheid sculpturen in Zuid-Azië. Van sommige is maar een enkele sculptuur bekend, of wordt vooral de huid afgebeeld zoals in het geval van de luipaard en antilopen. Rivierdolfijnen zijn met moeite te herkennen in een handvol makaras (watermonsters) en zeekoeien zijn helemaal nergens te vinden.

Het grootste aandeel van afgebeelde dieren betreft de grote huisdieren en de olifant. Vooral de dieren met een bijzondere status, hetzij in de maatschappij, hetzij in religie, zijn prominent aanwezig in heel Zuid-Azië, met de olifant als absolute topper, ${ }^{4}$ gevolgd door zeboestieren. ${ }^{5}$ De waterbuffel komt veelvuldig voor vanwege zijn rol als demon die door de hindoeïstische godin Durga gedood wordt (Durga Mahisasuramardini; afb. 2) en zijn connectie met Yama, de god van de dood. De enige uitzondering is de dromedaris, die ondanks zijn grote economisch belang maar mondjesmaat in beeldhouwwerk vereeuwigd is, iets wat geheel verklaard kan worden door zijn beperkte voorkomen: de (half)woestijnen van het noordwesten en sporadisch in $12^{\mathrm{e}}$ $14^{\mathrm{e}}$-eeuwse Zuid-Indiase hoofdsteden als geïmporteerde strijddieren. De uitgebeelde grote dieren zijn praktisch altijd versierd met bloemenkransen, kettingen en koorden, bellen, zadels (paarden), tapijten en/of zetels (dromedarissen, olifanten) (afb. 3). ${ }^{6}$ 
Afbeelding 1

Arjuna's Boetedoening, Mamallapuram, Tamil Nadu, $7^{e}$ - midden $\mathbf{8}^{e}$ eeuw. Foto Mark Blafkin

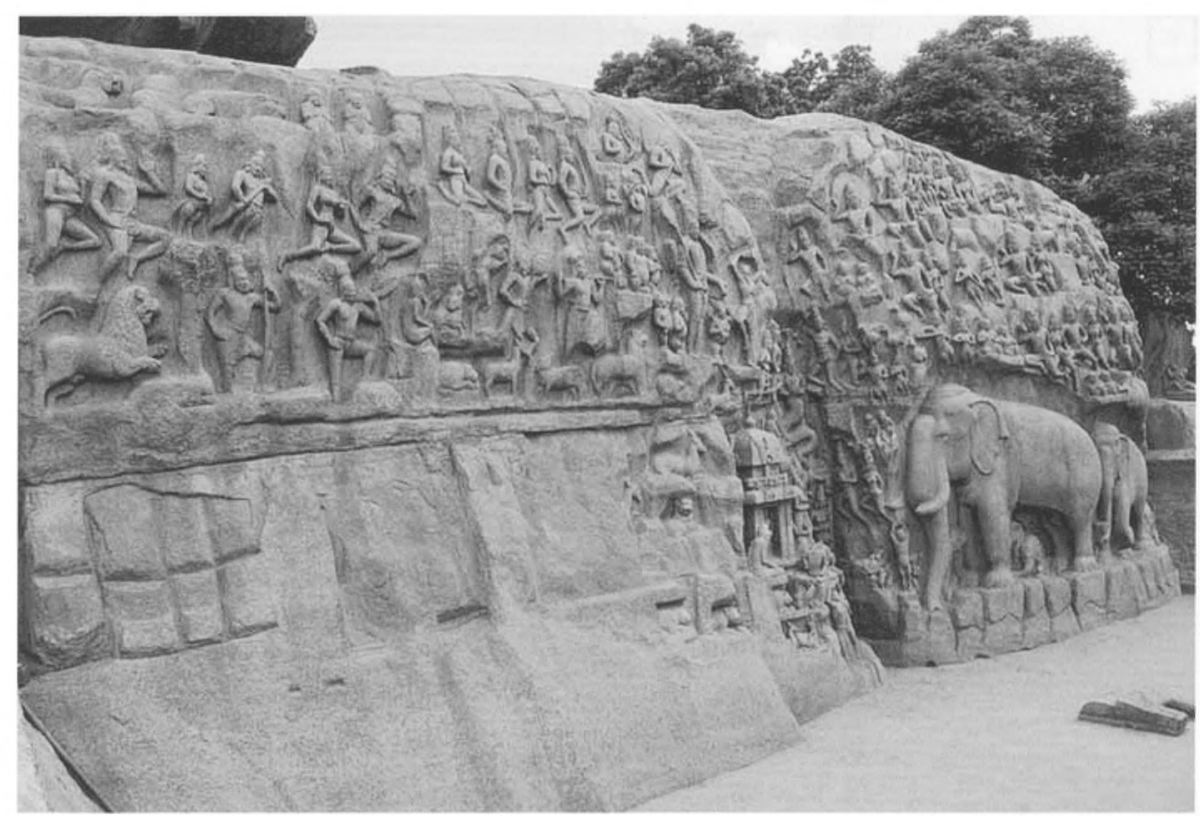

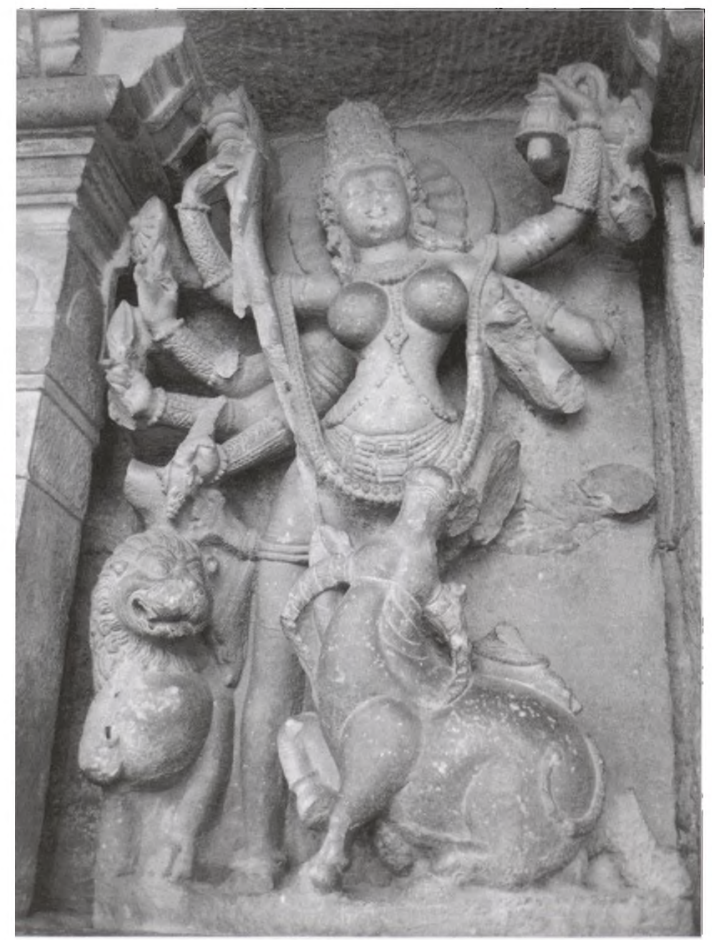

Afbeelding 2

Durga Mahisasuramardini, Durga tempel, Aihole, Karnataka, ca. 700-725. Foto M. Madhrani \&

S. Cama
Afbeelding 3

Indra's olifant Airavati,

Lakshminarasimha tempel,

Nuggihalla, Karnataka,

ca. 1246. Foto Sriram

Lakshminarayanan

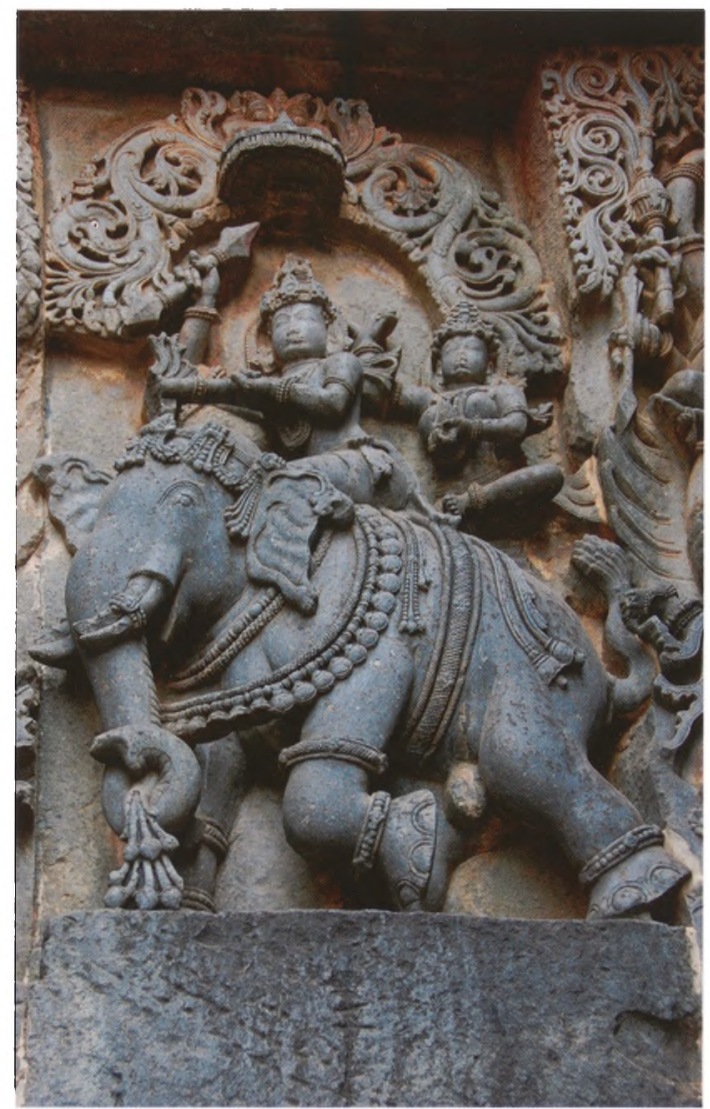


De kleinere en minder in aanzien staande huisdieren zoals honden, katten, geiten, schapen, mangoesten en varkens komen bijna niet voor in steensculpturen. Als dat al het geval is, dan in associatie met een godheid, meestal een mythe duidend, zoals de hond met Shiva, de kat met de zesde moedergodin Shasthi, de ram met de vruchtbaarheidsgod Naigamesha, de god van het vuur Agni en met de schoolgaande Boeddha, de mangoest met de god van de rijkdom Kubera en het varken met Vishnu's derde avatar; honden en katten figureren daarnaast nog in een paar volksverhalen.

\section{Tijdlijn van dierportretten}

Ruim vierduizend jaar lang worden dieren in Zuid-Azië in steensculpturen afgebeeld. De oudste bewijzen zijn in de vorm van speksteenzegels, gevonden in de Indus Vallei van het huidige Pakistan, behorend tot de Harappa-periode (circa 2300-1750 v.Chr.). Waar deze zegels voor dienden is niet zeker, maar waarschijnlijk werden ze in de handel gebruikt of misschien ook in rituelen. ${ }^{7}$ Het gros van deze zegels toont de afbeelding van een dier, hetzij realistisch of mythisch, met daarboven of daaronder een regel symbolen of tekens. De hoofdmoot van de zegels wordt gevormd door de zeboes (afb. 4), bizons en olifanten, gevolgd door neushoorns, tijgers,

\section{Afbeelding 4}

Zegel met zeboestier, Mohenjo-daro, Pakistan, ca. 2300-1750 v.Chr., Nationaal Museum, Karachi. Foto ASI, 19251930, met dank aan Instituut Kern, Leiden

\section{Afbeelding 5}

Zegel met pantserneushoorn, Mohenjo-daro, Pakistan, ca. 2300-1750 v.Chr., Nationaal Museum, Karachi. Foto ASI, 19251930, met dank aan Instituut Kern, Leiden
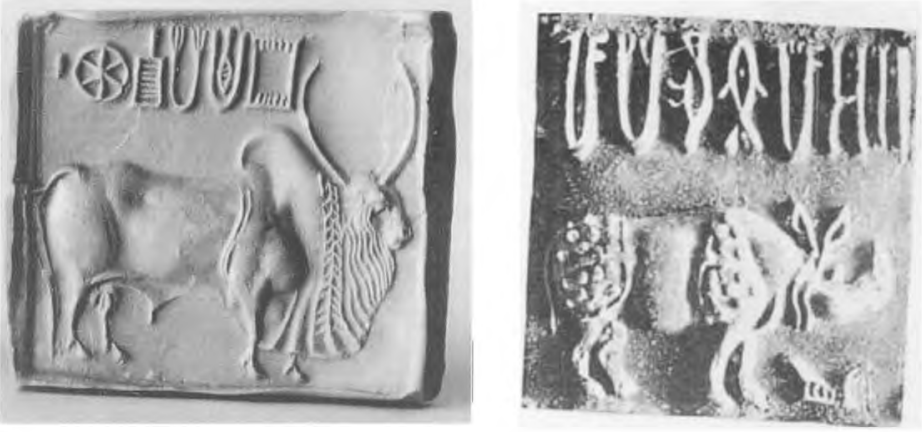

waterbuffels en zo af en toe een markhor, een krokodil of een leeuw; paarden en kamelen/dromedarissen ontbreken geheel. Van al die diersoorten werd alleen de mannelijke variant afgebeeld; vrouwtjes zijn nergens te bekennen. Ondanks hun miniatuur-afmeting zijn de dierfiguren vaak indrukwekkend realistisch en laten zij duidelijk zien dat de makers een scherp oog hadden voor de dieren in de wereld om hen heen. Een bewijs hiervoor zijn de neushoornzegels (afb. 5). De typisch geplooide huid met prominente knobbels is met precisie gekopieerd op de kleine zegels.

Een groot aantal zegels lijkt een zogenaamde eenhoorn af te beelden, maar dat is volgens mij een misvatting. Het is veel aannemelijker uit te gaan van een oeros die in profiel is afgebeeld, waarbij de twee hoorns over elkaar vallen. Oerossen hebben lange, naar voren gebogen hoorns, net als de zogenaamde eenhoorns. In die tijd zag de Indus Vallei er een heel stuk groener uit dan vandaag, en was bedekt met dichte bossen waarin dieren als oerossen, tijgers en bizons nog voorkwamen.

Niet alle dieren zijn te herleiden. Zo is er bijvoorbeeld een zegel met een dier met een lange nek en rondjes over zijn hele lichaam dat nog het meest lijkt ${ }^{2: 42 \mathrm{Am}}$ 
op een giraf. Echter, er is geen enkel bewijs van contact in die tijd met de culturen ten zuiden van de Sahara waar giraffen voorkomen. Een ander raadselachtig zegel toont een vreemd dier met een langharige vacht, naar boven gekrulde horens en een lange slurf tot op de grond. Het geheel lijkt nog het meest op een yak met een dik koord vastgebonden aan de snuit, maar zo'n type koord wordt op geen enkele andere zegel getoond.

\section{Afbeelding 6}

Zeboestier kapiteel, Rampurva, Bihar, $3^{e}$ eeuw v.Chr. Rashtrapati Bhavan, New Delhi. Foto ASI CC, 2022, 1919-1920, met dank aan Instituut Kern, Leiden

\section{Afbeelding 7}

Heldenstenen (devalis) opgedragen aan Pabuji, Kolu, Rajasthan, $17^{e}-18^{e}$ eeuw. Foto J. Kamphorst
$\mathrm{Na}$ de Harappa-periode valt er een archeologische stilte van ongeveer duizend jaar voor wat betreft de diersculpturen. Er zijn hier en daar wel wat verdwaalde post-Harappa resten, maar daar zijn geen dierzegels van bekend. Rond ongeveer 800 v.Chr. begon een nieuwe urbanisatieperiode in het noorden, afgaande op de archeologische overblijfselen van nederzettingen en versterkingen, maar ook daar zijn geen diersculpturen gevonden.

De allereerste post-Harappa gebeeldhouwde dierfiguren stammen uit de Maurya-dynastie (circa 321-185 v.Chr.), de grondleggers van het eerste grootschalige Indiase rijk dat ongeveer strekte van wat nu Afghanistan is tot in Centraal-India; alleen het zuiden viel buiten hun invloed. Hun diersculpturen zijn hoofdzakelijk in de vorm van kapitelen en abaci (afb. 6). Eén zo'n kapiteel, het beroemde leeuwenkwartet van Sarnath, Uttar Pradesh (circa
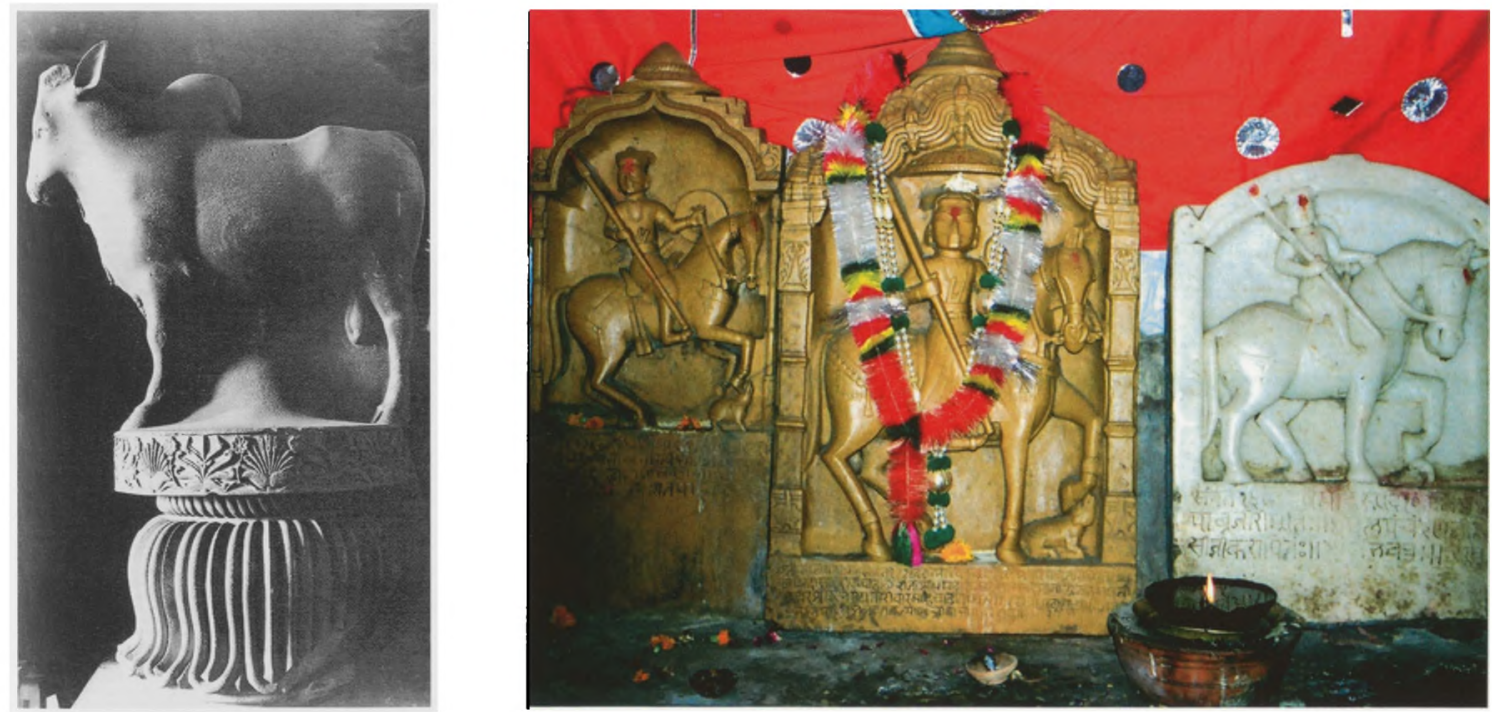

250 v.Chr.), dient nu als het officiële embleem van de Indiase republiek. De gedomesticeerde dieren van de Maurya-periode: zeboes, paarden en olifanten (weer alleen de mannelijke vertegenwoordigers), werden met grote zorg en oog voor detail uitgehouwen. De leeuwen daarentegen verschillen: ze zijn statisch en kunstmatig, in groot contrast met bijvoorbeeld het levendige galopperende paard van één van de abacussen.

Vanaf de Maurya-periode groeit het aantal bewaarde diersculpturen gestaag, variërend van decoratieve reliëfs tot vrijstaande beelden. Dieren spelen diverse rollen: als gelukbrengers op ornamenten, als dragers van hun goddelijke meesters (met of zonder die meester zelf), als hoofdrolspelers en $22: 42 \mathrm{AM}$ 
Afbeelding 8

Badende olifanten, Naga Pokuna, Isurumuni, ca. $6^{e}-10^{\circ}$ eeuw. Foto ASC, 767, 1922-1923, met dank aan Instituut Kern, Leiden figuranten in verhalende reliëfs, als vertegenwoordigers van de koninklijke macht, als deurbewakers van paleizen en tempels, of gewoon als ondersteuners van architectonisch onderdelen.

Zoals te verwachten is de overgrote meerderheid van de afgebeelde dieren anoniem. Slechts een handjevol is gebaseerd op een werkelijk bestaand, historisch dier. De beste voorbeelden zijn te vinden op de heldenstenen (devalis) die je overal in de Tharwoestijn, of de Grote Indiase Woestijn, in Rajasthan en Gujarat tegenkomt. Rajput helden of grote leiders die in navolging van een nobel doel stierven, zoals het terugwinnen van gestolen vee en het oplossen van conflicten met andere clans over waterputten, werden onsterfelijk gemaakt en vaak verheven tot (semi-)goddelijke status op zo'n heldensteen, afgebeeld rijdend op hun trouwe ros (afb. 7). ${ }^{8}$ Soms, afhankelijk van de omstandigheden van hun heldendood, nog met vee of een dromedaris erbij. Hun vrouw(en) staan er ook soms nog op, in geval ze levend verbrand werden op de crematiestapel van hun echtgenoot zodat ze de status van sati (goede vrouw) bereikten. Boven het geheel vind je vaak nog een maan of een zon, een indicatie van de afstamming van de Rajput held. ${ }^{9}$ De meeste helden of volksgoden zijn bij naam bekend, en dat geldt ook voor hun paarden, zoals bijvoorbeeld de merrie Kalmi of Kesar van Pabuji (14eeuw; afb. 7). ${ }^{10}$

In sommige gebieden valt een overdaad aan diersculpturen op, tenminste gedurende een bepaalde periode, terwijl in andere gebieden diermotieven slechts spaarzaam gebruikt lijken te zijn. Voorbeelden van een invasie van dierfiguren in steensculpturen zijn vooral te vinden in de omheiningen en

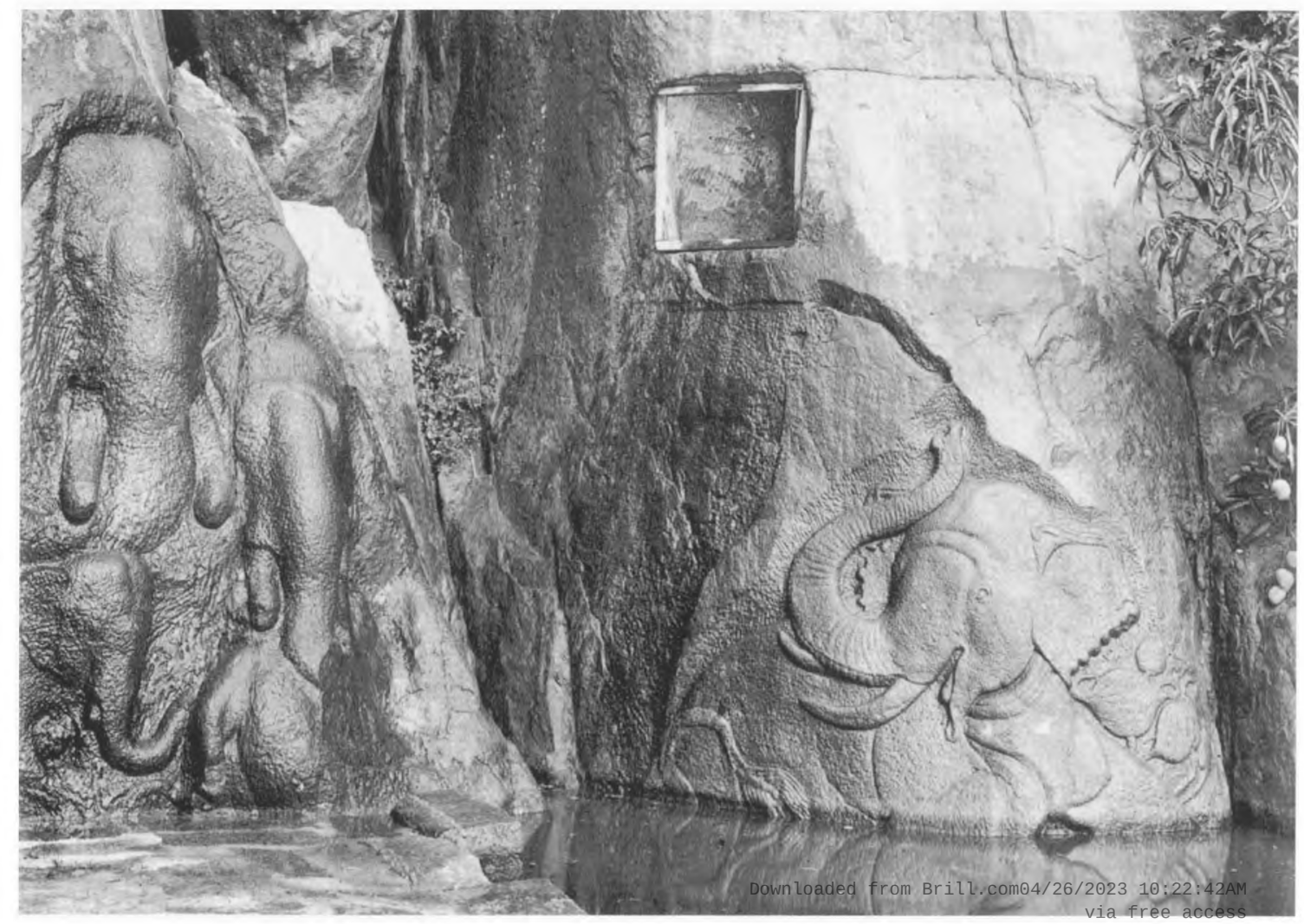


toegangspoorten rond boeddhistische stupas te Sanchi, Madhya Pradesh $\left(2^{\mathrm{e}}-1^{\mathrm{e}}\right.$ eeuw v.Chr.) en de hindoeïstische grotten, rotswanden en vrijstaande beelden te Mamallapuram, Tamil Nadu ( $7^{\mathrm{e}}-8^{\mathrm{e}}$ eeuw). Een veelheid van diersoorten, realistisch zowel als fantastisch, zijn hier uitgehouwen als stil bewijs van de vaardigheid van de kunstenaars van Sanchi en Mamallapuram. Dit is aanmerkelijk minder het geval bij de verder vergelijkbare stupa omheiningen en toegangspoorten van Amaravati, Andhra Pradesh ( $2^{\mathrm{e}}-3^{\mathrm{e}}$ eeuw). Ongetwijfeld is de kunst van Amaravati uniek en onovertrefbaar en het hele stupa complex was een wereldwonder in die tijd, maar de menselijke figuren overtreffen in aantal die van dierfiguren met het grootste gemak. De paar afgebeelde dieren die we er vinden zijn vaker wel dan niet van een mythische aard. Ook de boeddhistische architectuur van Sri Lanka van vóór de $10^{\mathrm{e}}$ eeuw is niet bijzonder rijk in diersculpturen. Sommige van deze zeldzame afgebeelde dieren zijn echter met buitengewone vaardigheid uitgehouwen en lijken net een stilstaand beeld uit een film, zoals de badende olifanten van de Naga Pokuna ( $6^{\mathrm{e}}-10^{\mathrm{e}}$ eeuw), een natuurlijk waterreservoir bij het Tisawewa meer bij Isurumuni (afb. 8).

Afbeelding 9

Sala vecht met de leeuw, Keshava tempel, Belur, Karnataka, ca. 1117 . Foto Anita Moorjani
Bijzonder weinig diersculpturen zijn terug te voeren tot de islamitische periode van heel Zuid-Azië tussen ruwweg de $12^{\mathrm{e}}$ en $18^{\mathrm{e}}$ eeuw. Ondanks de passie en wetenschappelijke interesse in de natuur in al haar vormen binnen de Islam, hun weerslag vindend in de miniatuurschilderingen, manuscriptillustraties, mozaïeken en inlegwerk, ${ }^{11}$ zijn diersculpturen uiterst zeldzaam en schijnen voornamelijk beperkt gebleven te zijn tot standbeelden van olifanten bij toegangspoorten. De decoratie van de islamitische architectuur in India is

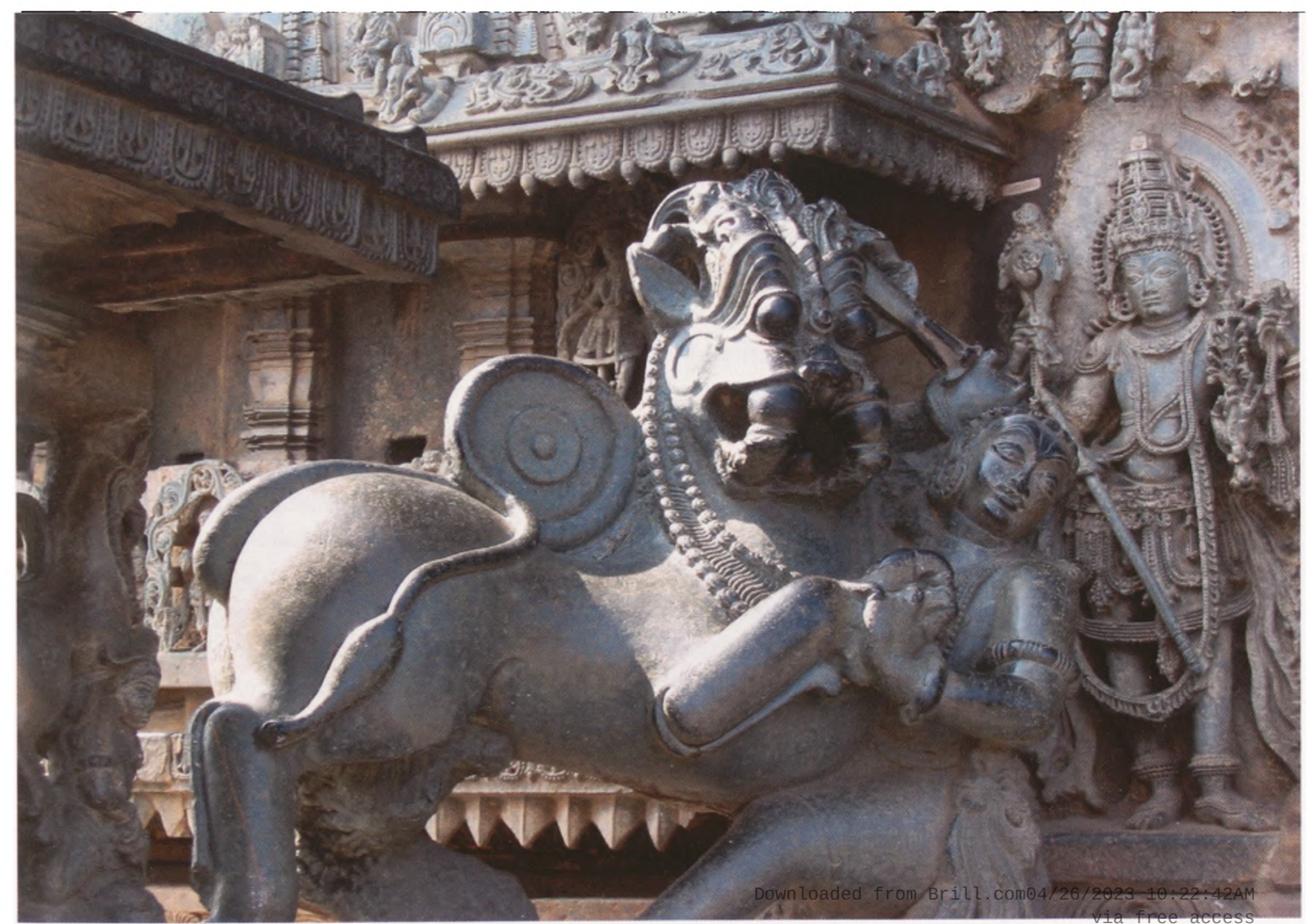


voornamelijk beperkt tot het strikt tweedimensionale vlak van schilderingen, tegelwerk, mozaïek en inlegwerk.

Hindoeïstische opdrachtgevers gingen in diezelfde periode door met het laten uitvoeren van monumentale sculpturen waarop dieren floreerden. Ze zijn soms vol leven en lijken zo los te kunnen breken uit hun stenen gevangenis van de $16^{\mathrm{e}}-17^{\mathrm{e}}$-eeuwse hindoeïstische tempels van Tamil Nadu. In andere gevallen zijn ze meer statisch, lomp en grotesk, zoals de vrijstaande, levensgrote paard- en olifantbeelden van de Zonnetempel te Konarak, Orissa (13 eeuw).

Gebonden aan allerlei beperkingen, waaronder niet alleen ervaring en kundigheid van de beeldhouwers zelf, maar ook de wensen en ideeën van de opdrachtgever, de heersende opvattingen en kennis van de natuur en niet te vergeten de eigenschappen van de steensoort zelf en de hoeveelheid beschikbare ruimte voor de sculptuur, beeldden de kunstenaars de dieren uit variërend van verbazingwekkend naturalistisch tot hogelijk gestileerd of totaal fantastisch. In het laatste geval kun je je afvragen of de kunstenaar(s) in kwestie wel ooit het dier in levende lijve hadden gezien. Dit is doorgaans het geval met de leeuw, een diersoort die sterk tot de verbeelding spreekt van het gewone volk maar dat in de meeste regio's slechts door weinigen is gezien. Fantastische details, niet aanwezig bij echte leeuwen, zijn bijvoorbeeld grote, uitpuilende ogen, rijen van stompe tanden, typisch voor planteneters, en soms zelfs een soort hoorns (afb. 9). De manen eindigen vaak in mooie krulletjes. Zeboestieren en -koeien waren daarentegen iedereen bekend en praktisch alle zeboe-sculpturen zijn naturalistisch, in de zin dat het dier zorgvuldig is uitgehouwen tot in de details. Realistische details die we in veel sculpturen terugvinden zijn bijvoorbeeld een sterk geplooid kossem of wam (de afhangende huidflap onder de nek en/of kin), de typische amandelvormige ogen en vooral de onmiskenbare bult op de bovenrug. Natuurlijk kan in principe iedere diersoort, of de beeldhouwer er nu mee vertrouwd is of niet, ook zeer gestileerd uitgebeeld worden. In deze gevallen zijn de gekozen details nauwkeurig uitgehouwen, maar onderhevig aan de wetten van stilering, zoals eenvoud van vorm, herhaling van identieke vormen en beperking tot de belangrijkste eigenschap. De totale vorm is vaak schematisch en veel details zijn weggelaten om de basisvorm of bepaalde eigenschappen uit te lichten en te benadrukken.

\section{Evolutie door de eeuwen heen}

De diermotieven evolueren bij het verstrijken van de tijd en volgen de algemene patronen van stilistische ontwikkelingen. Veranderingen in de afbeelding van dieren, of trends, zien we bijvoorbeeld in de paardsculpturen. De kleine, lompe en groothoofdige paarden van voor onze jaartelling (afb. 10) worden vervangen door grotere, elegantere en kleinhoofdige paarden iets na het midden van het tweede millenium. Deze trend zie je in de meeste regio's maar niet overal tegelijkertijd. Je kunt je echter afvragen of deze trend wel toegeschreven kan worden aan een verandering en evolutie in stijl. De mate waarin het paard zélf veranderde door de eeuwen compliceert het beeld aanzienlijk. Bovendien hadden de verschillende groepen een verschillende voorkeur voor paardenrassen. Stevige, dikbenige pony's zijn ideaal in de koude en ruige Himalaya terwijl middelgrote, fêlle, slankbenige en lang ${ }_{\text {ree }}$ access 


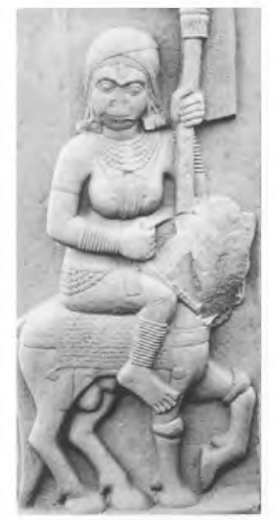

Afbeelding 10 Ruiter, oostelijke toegangspoort, Bharhut, Madhya Pradesh, ca. 100 v.Chr., Indian Museum, Calcutta. Foto 10 List 1900, 1062, met dank aan Instituut Kern, Leiden hoofdige paardjes als de Marwari en Kathiawari ${ }^{12}$ van de Rajputs ideaal zijn in de hete en vlakke Tharwoestijn.

In veel gevallen zijn de trends nog moeilijker op waarde te schatten of zijn zelfs niet eens zichtbaar, áls ze er al zijn. Dit is het geval met de neushoorn. Neushoornsculpturen zijn praktisch beperkt tot de Harappa-periode van de Indus Vallei (circa $2500-1750$ v.Chr.). ${ }^{13}$ De grote afwezigheid in latere periodes en andere regio's maakt het onmogelijk om een trend te definiëren. Het omgekeerde komt ook voor. Van bijvoorbeeld de leeuw en de olifant zijn zó ongelooflijk veel sculpturen die allemaal in meer of mindere mate van elkaar verschillen dat het moeilijk is om trends en patronen te ontdekken. De enige trend die wellicht aanwezig is in de leeuwensculpturen is dat de leeuw geleidelijk aan steeds fantastischer en mythischer wordt, misschien als een direct resultaat van hun snel afnemende aantallen, maar waarschijnlijk ook door een toenemende verstedelijking die de afstand tussen mensen en de natuur enorm vergroot.

Geen enkele duidelijke trend valt waar te nemen in de afbeeldingen van zeboes. Hun basisvorm met ruime, vaak geplooide huid, prominent kossem, kenmerkende bult op de schouders of bovenrug en grote, afhangende oren veranderde niet gedurende de ruim vier millennia die verstreken zijn sinds hun vroegste afbeelding op de zegels van de Indus Vallei. De duidelijke verschillen die aan te wijzen zijn tussen zeboesculpturen van de verschillende regio's en perioden zijn te wijten aan het bestaan van verschillende rassen en types, aangepast aan het lokale klimaat, gebruik en omgeving. Zo zijn er bijvoorbeeld tegenwoordig rassen met bol voorhoofd en korte hoorns in het noorden en rassen met een lang hoofd en lange, dunne, puntige hoorns in het zuiden van India. Een deel van deze rassen kan terug in de tijd gevolgd worden in steensculpturen van de betreffende regio tot de eerste eeuwen. Maar er trad ook evolutie op: de Indus Vallei-zeboe van vierduizend jaar geleden had de typische lange hoorns die we nu alleen in het zuiden zien. Het lijkt erop dat er selectie heeft plaats gevonden op korthoornigheid in het noorden, maar niet in het zuiden.

\section{Verwarringen en onduidelijkheden: de 'mrga'}

Vaak zijn de afgebeelde dieren weinig realistisch en missen de karakteristieke eigenschappen van de soort of vertonen een mengsel van kenmerken van twee verschillende soorten, wat het moeilijk maakt ze te identificeren.

Dit geldt in het bijzonder voor de dieren die traditioneel het Wiel van de Wet (dharmacakra) flankeren in uitbeeldingen van de Eerste Prediking van de Boeddha dan wel de Laatste Prediking van de Jina. Ze worden doorgaans uitgelegd als gazelles, antilopen of herten, en in analogie wordt dan het park waar de scène zich afspeelt (mrgavana) ook zo genoemd. De Pali en Sanskrit teksten voegen weinig toe, want al deze dieren worden eenvoudigweg respectievelijk miga of mrga genoemd, ${ }^{14}$ een woord dat niets meer of minder betekent dan het Engelse game, een dier waarop gejaagd kan worden.

Als we naar de overgeleverde afbeeldingen van deze episode kijken, dan zien we in de meeste gevallen een middelgroot evenhoevig dier met hoorns van verschillende lengte en vorm, typisch voor rundachtigen. De hoorns zijn altijd naar achteren gebogen en zijn ofwel kort, matig gekromd en glad of gegfoefd 

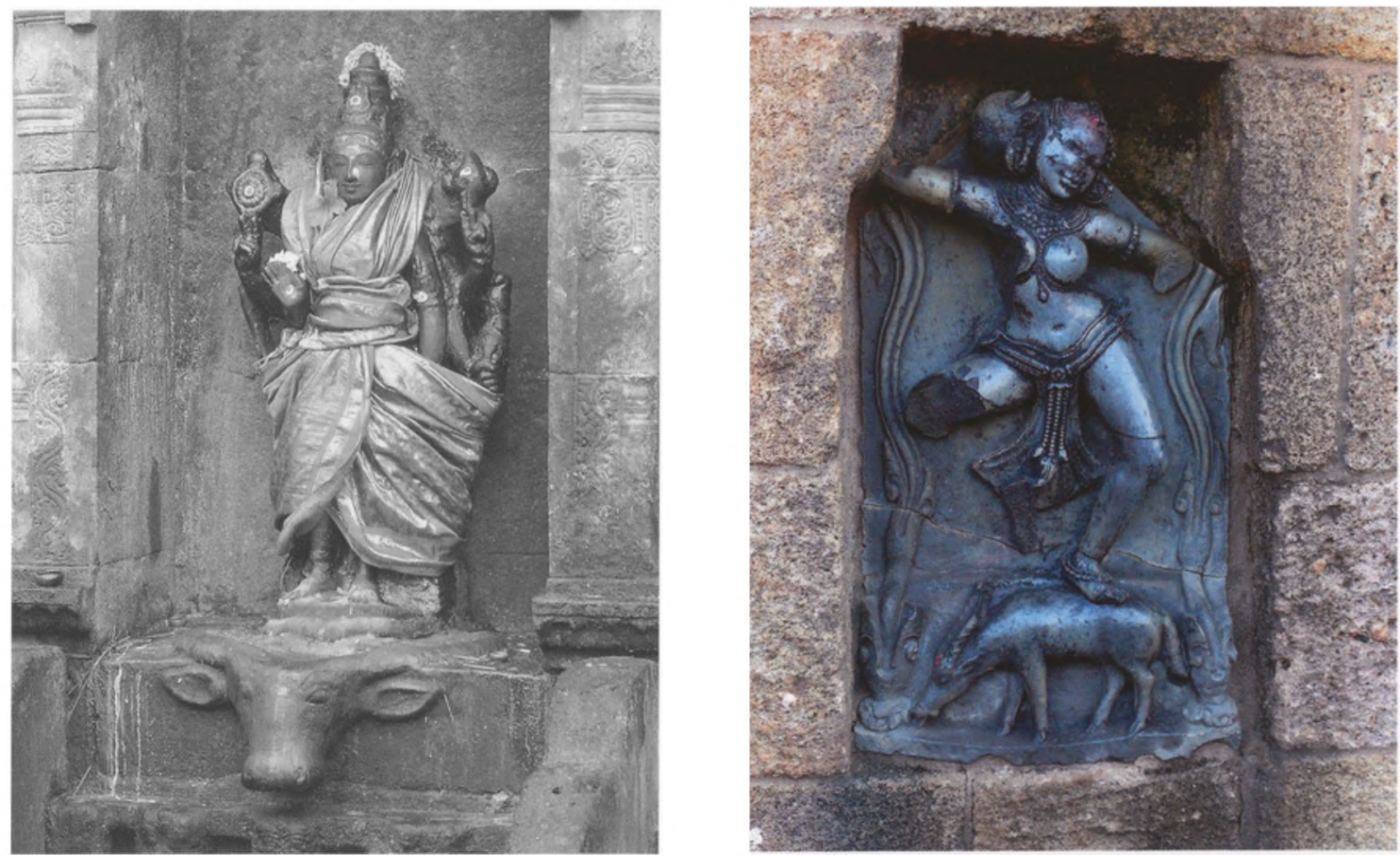

Afbeelding 1 Korravai op een buffelkop. Airavateshvara tempel, Darasuram, Tamil Nadu, mid-12eeuw. Foto Vicky Robinson

Afbeelding 12 Godin dansend op Indische antilope, Mukteshvara tempel, Bhubaneshwar, Orissa, $10^{\circ}$ eeuw.

Foto Rita Willaert ofwel langer en gegolfd. De eerste groep kan het best opgevat worden als gazelles of misschien als nilgai, de tweede groep als Indische antilopes, ook wel hertegeitantilopes of zwarte bokken genoemd. ${ }^{15}$ In slechts een heel klein aantal gevallen zijn de horens vertakt, en hebben we dus te maken met geweien, kenmerkend voor herten. ${ }^{16}$

Een zegel uit Mohenjo-daro in de Indus Vallei, Pakistan (circa 2300-1750 v.Chr.), populair (maar waarschijnlijk onjuist) bekend als de Pasupati zegel, toont een vergelijkbare scène, waarbij een schijnbaar mediterend figuur in een soort yoga-houding op een troon zit met een paar ibexen ervoor staand. Een direct verband is er natuurlijk niet te leggen tussen deze 'Pasupati zegel' en de reliëfs met de Eerste Prediking van de Buddha. Maar aan de andere kant kan er best een lange termijn traditie bestaan hebben in het noorden van Zuid-Azië waarin een paar evenhoevige wilde dieren, hetzij ibexen, hetzij gazelles of antilopes, hetzij. herten, met een spiritueel figuur geassocieerd wordt. Het buitengewoon kleine aantal herten in reliëfs doet vermoeden dat deze associatie rundachtigen betreft, en niet herten. Het ziet ernaar uit dat in het noorden en noordoosten ibexen en gazelles figureerden, en in het zuiden (Andhra Pradesh) bovendien Indische antilopes.

\section{Zeldzame voertuigen ('vahanas') en metgezellen}

De meeste godheden in India hebben een kenmerkend dier als voertuig (vahana). Het voert te ver om daar hier in detail op in te gaan, maar een paar uitzonderlijke voertuigen voor wat betreft steensculpturen wil ik hier belichten. Dat zijn dus niet het overbekende stierkalf van Shiva, de leeuw van Durga of de rat van Ganesha, maar de vrijwel niet bekende Indische antilope, kameel, jakhals en het wilde zwijh. aded from Brill.com04/26/2023 10:22:42AM 

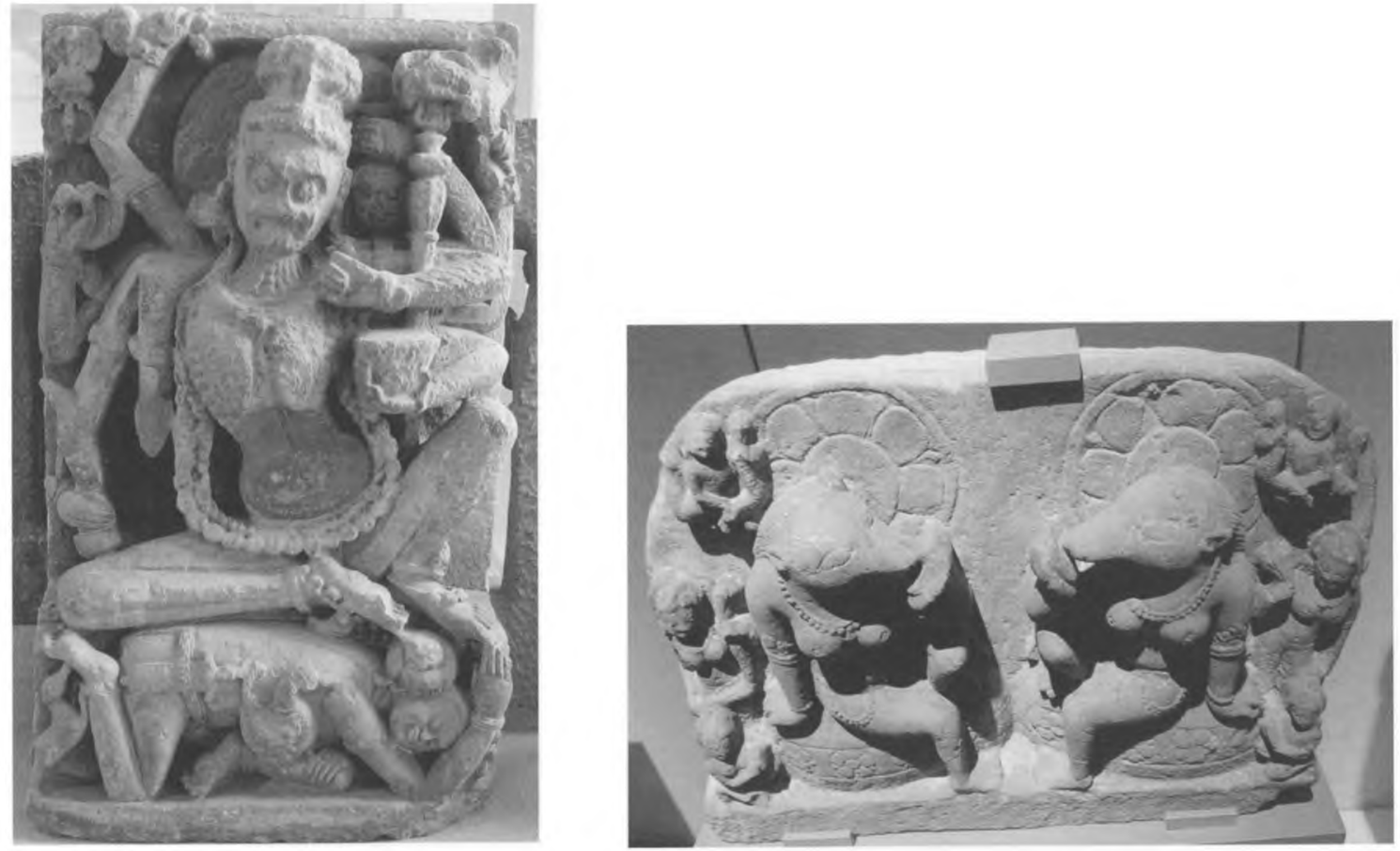

Afbeelding 13 Camunda met jakhals en uil, Bihar, ca. 800 , British Museum, London. Foto Kate Underwood

Afbeelding 14 Twee jakhalshoofdige yoginis, Midden India, $10^{\circ}-11^{\circ}$ eeuw, Staatliche Kunstsammlungen, 1.5922, Berlijn.

Foto C. Lyras
De Indische antilope of zwarte bok is de metgezel van de Zuid-Indiase godin Korravai, de godin van de overwinning (Glorie) en wel gezien als een incarnatie van de strijdlustige godin Durga. Meestal staat ze op een waterbuffelkop (afb. 11), maar ze is evengoed geassocieerd met de antilope, net als de lokale martiale godin Karni Mata van Rajasthan. Een andere godin met de antilope is een verder onbekende moedergodin zoals afgebeeld op de Mukteshvara tempel in Bhubaneshwar, Orissa ( $10^{\mathrm{e}}$ eeuw; afb. 12). De antilope is hier duidelijk herkenbaar aan zijn kurketrekkerhoorns en gespleten hoeven. De godin danst fanatiek op de rug van haar rijdier en is wellicht een martiale godin net als Korravai en Karni Mata.

De kameel is het rijdier van de boeddhistische wintergodin Hemantidevi op een sculptuur uit Bairhatta, Bangladesh $\left(8^{\mathrm{e}}-12^{\mathrm{e}}\right.$ eeuw). Het dier heeft duidelijk twee bulten en kan dus geen dromedaris zijn, hoewel je dat zou verwachten als je de gladde vacht ziet. Het lijkt de laatste keer te zijn dat de kameel in Zuid-Aziatische sculpturen voorkomt, want ze zijn verder alleen bekend uit Mathura ( $1^{\mathrm{e}}-3^{\mathrm{e}}$ eeuw), Gandhara ( $1^{\mathrm{e}}-4^{\mathrm{e}}$ eeuw) en Sanchi (circa 50-25 v.Chr.), maar nooit met een godheid als berijder.

De jakhals is het gezelschapsdier van Camunda in sculpturen na de $8^{\mathbf{e}}$ eeuw. $\mathrm{Ze}$ is een van de moedergodinnen en makkelijk te herkennen aan haar uitgemergelde figuur, hangende borsten en uitpuilende ogen. Om de sfeer verder op te vrolijken zit ze vaak op een lijk of demon (preta), en wordt ze vergezeld door een onheilspellende uil. Een mooi voorbeeld komt uit Bihar (circa 750-825; afb. 13). De jakhals kan ook andere schrikwekkende moedergodinnen vergezellen, zoals blijkt uit een openlucht-tempel voor de 64 yoginis (chausat yogini pitha) in Hirapur, Orissa (circa 900-925). ${ }^{17}$ Eén van de dames houdt een schedel in de ene hand en een zwaard in de andere. Een afgehiaktaccess 
hoofd ligt op haar voetstuk, en aan haar beide zijden staat een jakhals. Er zijn overigens ook jakhals-hoofdige godinnen, zoals Shivaduti en de twee yoginis zoals uitgebeeld op een reliëf uit Centraal-India ( $10^{\mathrm{e}}-11^{\mathrm{e}}$ eeuw; afb. 14). Ze zijn identiek maar gespiegeld en drinken (bloed?) uit een schedelkap, wat lijkt te wijzen op een tantrische culte.

De kar van de boeddhistische godin Marici wordt niet getrokken door zeven paarden, zoals de kar van de zonnegod Surya, maar door zeven zwijnen.

Een mooi voorbeeld is een stele van haar uit Varanasi, Uttar Pradesh $\left(8^{\mathrm{e}}-12^{\mathrm{e}}\right.$ eeuw; afb. 15), waar ze in de zogenaamde boogschuttershouding op haar kar

Afbeelding 15
Marici op haar
zwijnenkar, Varanasi,
Uttar Pradesh, 8-12
eeuw. Foto ASI DGA,
1903-1904, met dank
aan Instituut Kern,
Leiden

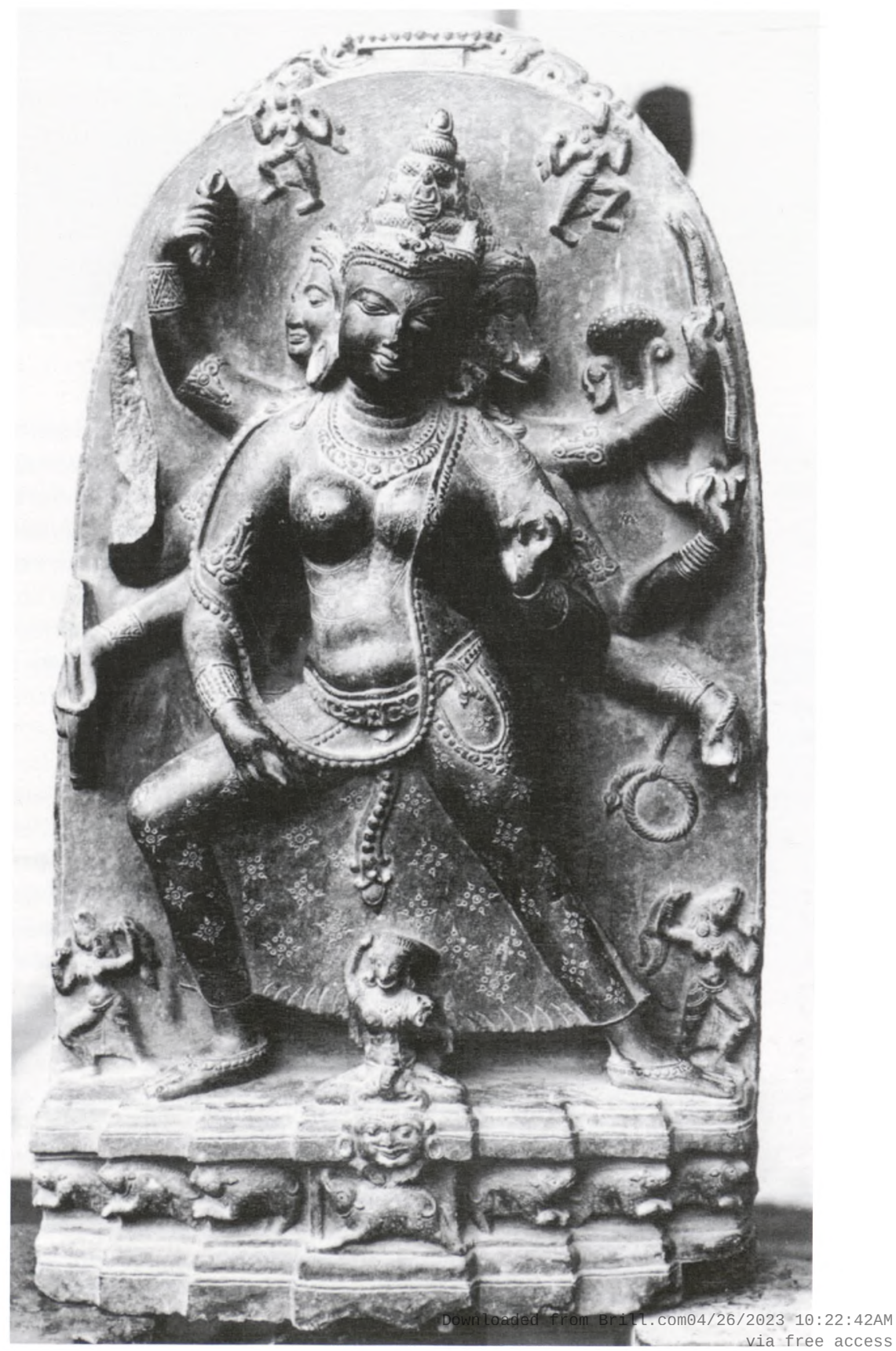


staat, iets wat typisch is voor de krodha (boosaardige) manifestaties van goden. Haar zeven zwijnen zijn realistisch uitgebeeld en worden geleid door een menner. Op sommige voetstukken, maar niet deze, is bovendien Rahu, symbool van de maansverduistering, te zien. Marici heeft zelf ook een zwijnshoofd (haar linker hoofd).

\section{Dieren in verhalende reliëfs}

India staat bekend om zijn dierenfabels, en het kan dan ook niet anders of een aantal van deze dierenfabels is uitgevoerd in steen. Jammer genoeg zijn de hoofdrolspelers vaak weinig realistisch uitgebeeld en moet het verhaal helpen de dieren juist te benoemen. Gelukkig zijn er toch een paar buiten-

Afbeelding 16 Verhalend medaillon, stupa omheining, Bharhut, Madhya Pradesh, ca. 100 v.Chr.. Foto I.O. List 1900, $1085,1874-1876$, met dank aan Instituut Kern, Leiden

Afbeelding 17 Verhalend medaillon, stupa omheining, Bharhut, Madhya Pradesh, ca. 100 v. Chr., Indian Museum, 407, Calcutta. Foto IO List 1900, 1033, met dank aan Instituut Kern, Leiden gewoon gedetailleerd uitgevoerde hoofdrolspelers te vinden. Een voorbeeld is te zien op een pilaster van de omheining van de stupa te Bharhut, Madhya Pradesh (circa 100 v.Chr.; afb. 16). Het medaillon illustreert het verhaal van drie vrienden die samen bij een bosmeertje woonden: een specht, een schildpad en een mrga (antilope/gazelle of hert). ${ }^{18}$ Op een nacht raakt de mrga gevangen in een strik. Om hem te bevrijden, knaagt de schildpad de valstrik door terwijl de specht de jager in zijn hut probeert te houden door ongelukskreten te slaken. De mrga ontsnapt, maar de schildpad was te uitgeput en werd gevangen door de jager. De mrga op zijn beurt nu trekt de aandacht van de jager en lokt hem diep het bos in zodat de schildpad kan ontsnappen. De mrga op het reliëf is eenvoudig te herkennen als een nilgai door zijn lange opgaande nek, korte prominente hoorntjes, zijn ietwat plompe voorkomen, en zijn grootte in verhouding tot die van de man.

Een in steen uitgebeeld verhaal dat mij persoonlijk aanspreekt is de Fabel van de Haas op de Maan. ${ }^{19}$ Het gaat over een stel dierenvrienden die de godheid Indra incognito op bezoek krijgen juist op de dag van de gastvrijheid
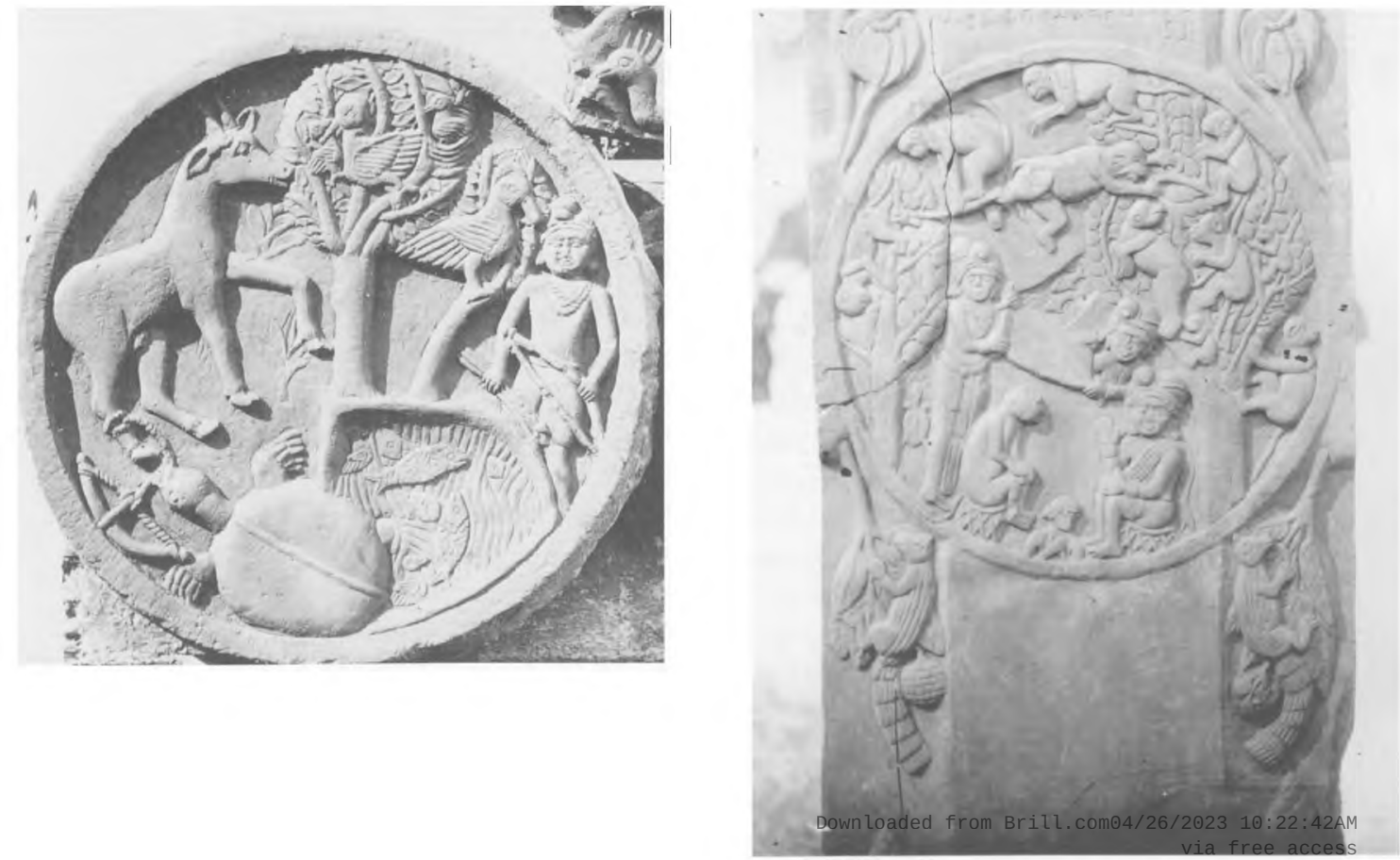
(uposatha). Alle dieren komen met een lekker hapje aandragen voor hun gast: de otter brengt vis, de jakhals een smakelijke hagedis en de aap wat mango's. Maar de haas kan natuurlijk geen gras aanbieden. Wat dan wel? Hij besluit in het vuur te springen en zichzelf aan te bieden als geroosterd boutje. Indra maakt zichzelf bekend en als dank voor deze uitzonderlijke opoffering maakt hij de haas onsterfelijk door hem af te beelden op de maan. Daarom heeft de schaduw op de maan in India de vorm van een haas. Het verhaal is terug te vinden in de ruïnes van de stupa's van Nagarjunakonda en Goli, Andhra Pradesh $\left(3^{\mathrm{e}}-4^{\mathrm{e}}\right.$ eeuw).

Een ander verhaal over een zichzelf wegcijferend dier is de Fabel van de Apenkoning. ${ }^{20}$ Op een dag ging de koning op apenjacht. De apen vluchtten weg, maar konden niet verder bij de rivier. De apenkoning strekte zichzelf uit over de rivier en vormde zo een brug voor zijn onderdanen. De laatste was zijn rivaal, die eens extra hard op de koning sprong om hem te verwonden. De koning aanschouwde het hele tafereel en werd erdoor geraakt. Hij zond onmiddellijk dienaars met een stretcher om de gewonde apenkoning op te halen om hem te verzorgen. Het verhaal is te vinden op diverse boeddhistische steensculpturen, zoals bijvoorbeeld op een pilaster van de omheining van de stupa van Bharhut, Madhya Pradesh (circa 100 v.Chr.; afb. 17), waar rhesusapen zijn afgebeeld. Tegenwoordig worden apen nog door veel tribale stammen gegeten, zoals de Kathodias van Udaipur, Rajasthan, de Lepchas in de Himalayas en de Bir-ho van Bihar en Orissa. Uit het verhaal blijkt dat dit gebruik vroeger veel algemener was en dat ook koningen op apenjacht gingen.

\section{Conclusie}

Welke zoogdieren kunnen we nu verwachten in Zuid-Aziatische steensculpturen? De overweldigende meerderheid behoort tot gedomesticeerde of getemde soorten: zeboes, waterbuffels, geiten en schapen, varkens, paarden, olifanten en honden. Zeldzaam, en vrijwel beperkt tot het noordwesten van de eerste eeuwen (Gandhara), zijn kamelen en dromedarissen. Wilde dieren zijn nog moeilijker terug te vinden in steensculpturen, behalve de alomtegenwoordige leeuw. ${ }^{21}$ De overige afgebeelde wilde dieren vallen voor het grootste deel in de categorie jachtwild: Indische antilopes, herten, wilde geiten, gazelles, tahrs, ibexen en wilde zwijnen. De rest wordt opgevuld door jakhalzen, rode honden, apen, wilde katten, hazen, otters, beren, luipaarden, rivierdolfijnen, en vossen. Per diersoort gaat het hier veelal maar om een handjevol sculpturen of nog minder. Gestreepte grondeekhoorns (afb. 17 onder het medaillon) en diverse soorten ratten en muizen, ${ }^{22}$ ook al leven deze in of rond de dorpen en in de velden zijn nog zeldzamer in sculptuur, op een enkele uitzondering na: de zwarte rat is uitbundig afgebeeld op de Karni Mata tempel in Deshnok, Rajasthan ( $20^{e}$ eeuw), waar ze vereerd worden. Een aantal dieren werd in het verre verleden wel uitgehouwen, maar later niet meer of in een enkel geval. Dat zijn de neushoorn, de Indische bizon, de nilgai, de markhor, de tapir en de tijger, waarschijnlijk gerelateerd aan hun drastisch afgenomen aantal in het wild. Alleen de nilgai komt tegenwoordig nog vrij veel voor in gecultiveerde velden. De grote afwezigen zijn jachtluipaard, hyena, Indisch schubdier of pangolin, muskushert en vleermuizen. Geen enkel mij bekende steensculptuur beeldt een van hen uit, ondanks hun bekendheid. 
1. A.A.E. van der Geer, Anlmals in Stone, Indian fauna sculptured through time, Leiden, 2008, pp. 1-434.

2. J. Harle, The Art and Architecture of the Indian subcontinent, Harmondsworth, Middlesex, 1987, p. 282. Waarom noch het zwijn noch het gedomesticeerde varken in Mamallapuram te vinden is, is een raadsel. Elders komen ze namelijk wel voor, zoals op decoraties van de stupa in Nagarjunakonda, Andhra Pradesh ( $3^{e}$ eeuw), als vorstelijk symbool in Aihole, Karnataka ( $7^{\mathrm{e}}$ eeuw) en op verschillende reliëfs met jachtscènes overal in India. In religieuze context komt het zwijn veel vaker voor, en dan vooral in relatie tot Vishnu's avatar als Varaha en zijn shakti Varahi.

3. Het gros der afgebeelde apen betreft Hanuman, de aanvoerder der apen en zoon van de windgod Vayu in het Ramayana, vooral in Zuid-India. Meestal is hij dan een langoer, in zeldzame gevallen een rhesus-aap.

4. De olifant is het vaakst afgebeelde dier in steensculpturen omdat de olifant meerdere rollen of aspecten vervult. De olifant is het symbool van koninklijke pracht en praal, van de geboorte van de Boeddha, en van regen. De olifant draagt de regengod Indra en acht olifanten samen dragen de windrichtingen. Ze worden gebruikt in het leger en als bewakers van ingangen en stadspoorten. En last but not least, Ganesha, zoon van Shiva en één van de meest populaire hindoegoden, heeft een olifantenhoofd.

5. Zeboekoeien worden vrijwel niet afgebeeld en vrijwel geheel beperkt tot verhalende reliëfs waarin ze een bescheiden bijrol vervullen als onderdeel van een kudde of hun kalfje verzorgend. Stieren daarentegen vervullen een actieve rol in verhalende reliefs en worden daarnaast al vierduizend jaar zelfstandig afgebeeld. Een zeer groot deel van de stiersculpturen betreft uiteraard het stierkalfje van Shiva met zijn ronde hoofd, brede snoet, (zeer) kleine bult en extreem korte hoorntjes, duidend op zijn jeugdigheid; alleen zijn hangende oren verraden nog zijn zeboe-afstamming.

6 . Voorbeelden van paarden zonder enig type van tuig zijn moeilijk te vinden; zeldzame voorbeelden zijn de abacus van de leeuwenpilaar van Sarnath, Uttar Pradesh ( $3^{\mathrm{e}}$ eeuw v.Chr.) en een paneel met het veulentje Kanthaka (het latere paard van prins Siddhartha) en zijn moeder, uit Gandhara ( $1^{\mathrm{e}}-^{\mathrm{e}}$ eeuw n.Chr.).

7. U. Franke-Vogt, 'Die Glyptik der Harappa-Kultur', Vergessene Städte am Indus (1987), p. 193; S. Atre, 'Harappan seal motifs and the animal retinue', Bulletin of the Deccan College Research Institute 49 (1990), pp. 43-51.

8. J. Kamphorst, 'The deification of South Asian Epic Heroes: Methodological Implications', in J. Jansen en H. Maier, Epic Adventures. Heroic Narrative in the Oral Performance Traditions of Four Continents, Muenster, 2004, pp. 89-98.

9. Sommige Rajput families herleiden hun afkomst tot de maan (chandravamshi), andere tot de zon (suryavamshi), en een minderheid tot mythische slangen (nagavamshi).

10. J. Kamphorst, 'The Warrior-hero Pabuji', in W. Callewaert en D. Taillieu, Devotional Literature in South Asia; Current Research 1997-2000, New Delhi, 2002, hoofdstuk 18.

11. Zie bijvoorbeeld R. Nath, 'Depiction of animate motifs at the tomb of I'timad-udDaulah at Agra', Islamic Culture 47/ 4 (1973), pp. 289-300; S. Parihar, 'Depiction of animate motifs on the Muslim monuments of the (East) Punjab \& Haryana - a survey', Joumal of the Pakistan Historical Society 40/ 3 (1992), pp. 185-193.

12. Deze inheemse Indiase paardenrassen hebben een groter uithoudingsvermogen in hun natuurlijke omgeving dan de meeste grote rassen zoals die van de Engelsen en veel Moghuls. Ze lijken in uiterlijk veel op khurs of onagers (Equus hemionus), de wilde paardjes van de Tharwoestijn en aangrenzende woestijngebieden tot in Iran. Ze worden ook wel wilde ezels genoemd, maar ze zijn niet direct verwant aan ezels. Ware wilde ezels (Equus asinus, Equus africanus) komen alleen in Afrika voor. Halfezels is een nóg ongelukkiger term, want deze impliceert een soort bastaardkruising tussen ezels en paarden.

13. Neushoornsculpturen bijvoorbeeld zijn voorzover mij bekend geheel beperkt tot de 
speksteenzegels van de Indus Vallei (circa $2300-1750$ v.Chr.), de railing rond de kleine stupa van Sanchi, Madhya Pradesh ( $2^{\mathrm{e}}$ eeuw v.Chr.), de Siddhi Lakshmi tempel te Bhaktapur in Nepal ( $17^{\mathrm{e}}$ eeuw) en de moderne Vredesstupa (Shanti stupa) bij Bhubaneshwar, Orissa (1972).

14. Ook Shiva heeft een mrga als kenmerkend attribuut in verscheidene verschijningsvormen (Somaskandamurti, Lingodbhavamurti, Candeshanugrahamurti, Bhikshatanamurti). Het diertje is minuscuul en draagt geen hoorns of een gewei. Hoogstwaarschijnlijk gaat het hier om het Indiase gevlekte dwerghert (Moschiola indica), behalve in het geval van Dakshinamurti, waar het eerder om jonge gevlekte chitals of axisherten (Axis axis) gaat. Het dwerghert leeft diep in het bos en is alleen 's nachts actief; een geschikt attribuut voor een ascetische godheid.

15. Sculpturen van gazelles naast het Wiel of voor de troon van een predikende Boeddha zijn gevonden in Gandhara (diverse sites; $1^{\mathrm{e}}-4^{\mathrm{e}}$ eeuw), Andhra Pradesh (Nagarjunakonda, Amaravati; $1^{\mathrm{e}}-3^{\mathrm{e}}$ eeuw). Er zijn maar twee sculpturen van nilgai in combinatie met het Wiel, eentje uit Gandhara (Loriyan Tangai; c. 50-250) en eentje uit Uttar Pradesh (Mathura; circa 0-100). Sculpturen van Indische antilopen het Wiel of de lege troon flankerend zijn alleen gevonden in Andhra Pradesh (Nagarjunakonda, Goli; $3^{e}-4^{e}$ eeuw) en Bihar (Rajgir; $7^{e}$ eeuw). Indische antilopen als indicators voor het 'hertenpark' figuren in Madhya Pradesh (Sanchi; circa 50-25 v.Chr.) en het Wiel van de Jina flankerend in Uttar Pradesh (onbekende site; $10^{\mathrm{e}}-13^{\mathrm{e}}$ eeuw)

16. Sculpturen van herten naast het Wiel of voor de troon zijn alleen gevonden in Madhya Pradesh (Bharhut; circa 100 v.Chr.) en Uttar Pradesh (Sarnath, $6^{\mathrm{e}}-^{\mathrm{e}}$ eeuw).

17. Vergelijkbare $10^{e}$-eeuwse Chausat Yogini pithas zijn gevonden in Bheraghat bij Jabalpur en in Khajuraho (Madhya Pradesh).

18. Kurumgamiga Jataka, Pali Jataka 206.

19. Shasha Jataka, Shashapandita Jataka, Pali Jataka 87.

20. Mahakapi Jataka, Rajovada Jataka, Pali Jataka 407. Het verhaal bestaat, net als zoveel verhalen, in een aantal versies. In een daarvan wil de koning alleen maar de mango's eten van de boom waarin de apen leven. Hij beveelt zijn dienaren de apen te doden omdat ze hem storen. Aangezien het eten van apen zo wijdverbreid is onder de meeste tribale stammen, lijkt het erop dat deze fruitige versie een latere, boeddhistische aanpassing is.

21. Pijnlijk genoeg zijn er tegenwoordig meer leeuwen in steensculpturen overgebleven dan in het wild. Hun toename in beeldhouwwerken lijkt gepaard te gaan met hun afname in de natuur.

22. Dit geldt niet zozeer voor Ganesha's rijdier de bandicoot rat, alhoewel maar op een paar afbeeldingen van Ganesha zijn rijdier te zien is. 